\title{
Educação superior no período noturno no Brasil: políticas, intenções e omissões
}

\author{
Iraíde Marques de Freitas Barreiro \\ Armando Terribili Filho
}

\section{Resumo}

Neste artigo analisa-se a oferta de vagas para o período noturno nos cursos de graduação da educação superior no país, com foco nas universidades públicas estaduais paulistas, a fim de se verificar como estas têm atendido à exigência da Constituição Paulista no sentido de se ofertar pelo menos um terço do total de suas vagas a este período. Avalia-se o impacto dessa exigência no contexto maior da oferta de vagas para a educação superior no país, considerando que a Reforma Universitária em trâmite propõe este mesmo índice para as universidades federais. Uma retrospectiva histórica apresenta a origem da educação superior no país, a presença exclusiva das instituições públicas até meados do século $X X$, a entrada das instituições religiosas no setor privado em 1946, e os desdobramentos da Reforma Universitária de 1968, marco da expansão do setor privado, que contempla atualmente $71,7 \%$ das 4,1 milhões de matrículas em cursos de gra- duação no país. As reflexões indicam que a expansão da educação superior deve priorizar o crescimento da oferta de vagas no sistema público, buscando uma melhor relação de vagas entre o sistema público e o privado, com ênfase nas demandas crescentes do período noturno, visando a um projeto maior de desenvolvimento do país, ordenado pelo Estado e alicerçado na valorização da Educação.

Palavras-chave: Educação superior. Período noturno. Oferta de vagas. Políticas públicas.

\section{Abstract Higher education in} night courses in Brazil: policies, intentions, and omissions

This paper analyzes the supplying of enrollment vacancies in undergraduate night courses in Brazil, 
focusing the public universities of São Paulo State, in order to check how such universities have complied with the requirements of São Paulo State Constitution by reserving at least onethird of such vacancies for the night courses. One weighs the impact of such requirements in the wider context of enrollment vacancies in higher educational institutions in Brazil, taking into consideration the fact that the University Reform still in process proposes the same ratio to federal universities. A historical review explains the origin of higher education in our country, the exclusive predominance of public institutions until the beginning of the $20^{\text {th }}$ century, the emergence of religious institutions within the private sector in 1946, and the development of the University Reform in 1968, a landmark in the expansion of the private sector which nowadays comprises $71.7 \%$ out of the 4.1 million enrollment vacancies meant for the undergraduate night courses in Brazil. Pondering upon the issue recommends that the expansion of higher education should give priority to the growth of enrollment vacancies within the public school system, trying to reach a better balanced ratio of such vacancies between the public and the private sectors, emphasizing the increasing demand for night courses, having in mind a more extensive development program in the country, commanded by the State and founded on the advancement of Education.

Keywords: Higher education. Night courses. Supplying of enrollment vacancies. Public policies.

\section{Resumen}

Enseñanza superior en el período nocturno en Brasil: políticas, intenciones y omisiones

En este trabajo se analiza la oferta de vacantes en el período nocturno en la enseñanza superior en Brasil, enfocando las universidades estaduales de São Paulo, con el objetivo de verificar como están atendiendo la ley contenida en la constitución del Estado de São Paulo, que exige la oferta mínima de la tersa parte del total de las vacantes a este período. Una evaluación del impacto de esta exigencia en el contexto nacional de oferta de vacantes a la enseñanza superior, considerando que la reforma universitaria que está siendo discutida actualmente, propone este mismo índice para las universidades federales. Una retrospectiva histórica presenta el origen de la educación superior en Brasil hace cerca de 200 años, la presencia exclusiva de las instituciones públicas hasta mediados del siglo XX, la entrada de las instituciones religiosas en el sector privado en 1946 y la Reforma Universitaria de 1968 que fue el marco del período de la expansión cuantitativa de la educación superior en el país, culminando con un amplio predominio del sector privado, que contempla actualmente $71,7 \%$ de las 4. 163. 733 matrículas, de acuerdo con el último censo oficial anual. Las reflexiones indican que la expansión de la enseñanza superior debe dar prioridad al crecimiento de la oferta de vacantes en el sistema público, buscando una mejor relación de vacantes entre el sistema público y el privado, con énfasis en las demandas crecientes de la sociedad para el período nocturno, con visión de un gran 
proyecto de desarrollo de la nación, ordenado por el Estado y apoyado por la valoración de la Educación.

Palabras clave: Educación superior. Período nocturno. Oferta de vacantes. Políticas públicas.

Neste artigo analisa-se a oferta de vagas para o ensino superior noturno' no Brasil, com foco nas universidades públicas estaduais paulistas: Universidade Estadual Paulista "Júlio de Mesquita Filho" - UNESP, Universidade Estadual de Campinas - UNICAMP, e Universidade de São Paulo - USP, a fim de se verificar como estas têm atendido à exigência da Constituição Paulista no sentido de ofertar pelo menos um terço do total de suas vagas ao período noturno. Avalia-se ainda, o impacto que essa exigência representa no contexto maior da oferta de vagas para o ensino superior no país, considerando que a Reforma Universitária em trâmite também propõe este mesmo índice para as universidades federais. As políticas para a ampliação de vagas pelas universidades públicas, com destaque para o ensino noturno e a expansão explosiva de matrículas no ensino particular, podem ser mais bem avaliadas, a partir da compreensão dos mecanismos que desencadearam reformas no ensino superior e de sua relação com o processo de reforma do Estado, orientado pela lógica neoliberal.

Nos anos 90, as políticas públicas são reorientadas por meio da reforma do Estado que altera os padrões de intervenção estatal, redireciona mecanismos e formas de gestão, de modo a ajustar as políticas públicas, e em especial, as educacionais, às orientações dos organismos multilaterais. Tais ações, no campo da educação, se expressam na aprovação de leis, sendo a principal, a Lei de Diretrizes e Bases da Educação Nacional - LDB (BRASIL, 1996), Lei $n^{\circ}$. 9.394, de 20 de dezembro de 1996. Compondo um movimento mais amplo de alinhamento de paradigmas no campo da globalização, como condição de inserção das sociedades na modernidade, a educação superior passa a ser pressionada a atender tais demandas. Vaidergorn (2001, p. 85) aponta que:

[...] a educação superior, distintamente da educação básica (fornecedora da mão-de-obra treinável) é estratégica, dentro dessa concepção de modernidade globalizada. Um dos fundamentos da inserção no mundo competitivo atual é o domínio e a produção do conhecimento, que passam a ser um bem - identificando-se aí um dos papéis a que se destinam as universidades.

A condição da educação superior é apontada por Santos (1995) ao analisar criticamente a posição das universidades públicas nas sociedades contemporâneas, tendo em vista os questionamentos feitos tanto pela sociedade, quanto pelo Estado, de modo que se desencadeia profunda mudança estrutural nas universidades públicas, sendo possível identificar três crises ao longo dos anos 90. A primeira, a crise da "hegemonia", resultante das contradições da universidade enquanto lugar privilegiado da produção do saber e

\footnotetext{
' De acordo com a Lei de Diretrizes e Bases da Educação Nacional (BRASIL, 1996), a educação escolar brasileira está dividida em educação básica e educação superior. A educação básica é composta por: educação infantil (creches até 3 anos de idade e préescolas entre 4 e 6 anos de idade), ensino fundamental (mínimo de 8 anos) e ensino médio (mínimo de 3 anos). A educação superior, por sua vez, organiza-se em cursos e programas, que são: cursos seqüenciais, cursos de graduação, de pós-graduação e de extensão. Para efeito deste trabalho, utiliza-se o termo "ensino superior noturno" para designar aspectos relacionados a cursos presenciais de graduação da educação superior no período noturno.
} 
do conhecimento científico e de outras pautas que lhe foram incorporadas no decorrer do século $X X$, tendo em vista as exigências sociais emergentes e a interpelação no sentido de participar do desenvolvimento tecnológico do sistema produtivo (SANTOS, 1995, p. 193). A segunda crise, a da "legitimidade", se explicita "no momento em que se torna visível que a educação superior e a alta cultura são prerrogativas das classes superiores, altas" (SANTOS, 1995, p. 211 1). Dessa forma, a universidade passa a conviver com políticas de democratização e a reivindicação de oportunidade para os filhos das classes sociais menos abastadas - seu acesso transforma-se em direitos para todos, deixando de ser direito exclusivo da elite. A terceira crise, a "institucional", que tem em si o agravamento das duas primeiras, é decorrente da contradição entre a reivindicação da autonomia na definição de valores e objetivos da universidade e a pressão crescente em submetê-la a critérios de eficiência, de caráter empresarial ou de responsabilidade social.

De acordo com Derek (2003 apud SIQUEIRA, 2005), o êxito de uma universidade tem como base sua capacidade em superar o desafio de evitar o risco da comercialização do ensino, protegendo sua reputação frente à sociedade, compatibilizando sua autonomia, responsabilidade social e valores culturais com interesses políticos e econômicos.

Aronowitz (2005, p. 16) critica o ensino superior de massa, caracterizando-o como algo que mascara o desemprego e a escassa oferta de empregos, explicável por sua rápida expansão nas três últimas décadas, período de estagnação econômica crônica, desindustrialização e proliferação de empregos mal remunerados na área de senviços; afirma, de forma sucinta:

Em lugar de construírem um sinal de habilitações crescentes e de alargamento de oportunidades, o desabrochar das universidades e os ingressos nela efetuados traduzem a mudança de tendências econômicas e políticas.

As crises vivenciadas pela universidade não estão descoladas dos acontecimentos e transformações da sociedade, nos contextos nacional e internacional. Nesse sentido, a falta de prioridade no estabelecimento de políticas públicas para a universidade é resultado de um arrefecimento nas proposições de políticas sociais (educação, saúde, previdência) devido às diretrizes neoliberais, que a partir dos anos 80 se internacionalizaram. Em decorrência desse modelo de desenvolvimento, as debilidades institucionais da universidade pública foram mais facilmente explicitadas e, ao contrário de servirem para a elaboração de um programa político-pedagógico de reforma da universidade, tal exposição serviu "para justificar a abertura generalizada do bem público universitário à exploração comercial" (SANTOS, 1995).

Santos (2004, p. 16-18) chama a atenção para dois processos marcantes que se consolidam em meados da década de 90 tornando-se, segundo ele, duas faces da mesma moeda: "o desinvestimento do Estado na universidade pública e a globalização mercantil na universidade". Ambos formam no dia-a-dia um projeto de política universitária que vem mudando o modo como o bem público é produzido, levando à "mercadorização" da universidade. É neste contexto de mudanças da destinação da universidade pública, de ampliação de vagas para o ensino superior particular, com destaque para o ensino noturno que se situam as reflexões deste trabalho. 


\section{A educação superior: o setor público e o privado}

Os cursos superiores não teológicos foram criados durante a permanência da família real portuguesa no Brasil, no período de 1808-1821, com um sentido profissional prático, distinguindo-se a Academia Real da Marinha, em 1808, e a Academia Real Militar, em 1810. Os cursos de cirurgia, anatomia e medicina tinham por objetivo formar cirurgiões e médicos para a Marinha e o Exército. A primeira instituição que se apresentou como universidade no país foi fundada em Manaus em 1909.

A história da educação superior no Brasil e das universidades brasileiras apresenta particularidades quanto à sua concepção, evolução e situação atual. A universidade brasileira foi concebida por uma elite intelectual laica, inserida em um movimento de modernização cultural e educacional no país (SAMPAIO, 2000). Somente em 1946 surgem as primeiras universidades particulares no Brasil: Pontifícia Universidade Católica do Rio de Janeiro e Pontifícia Universidade Católica de São Paulo. Outras instituições também religiosas surgem paulatinamente em Recife, Campinas, Goiânia, Belo Horizonte, Curitiba e Pelotas. Até a década de 60 a educação superior no país restringia-se preponderantemente à iniciativa pública e $\mathrm{O}$ acesso às classes sociais mais baixas era restrito. A partir da década 70 inicia-se um processo de expansão e popularização da educação superior, caracterizado pelo crescimento do setor privado, favorecido pelas políticas definidas nos governos pós-revolução de 1964.

De acordo com o Censo Anual da Educação Superior de 2004, realizado anualmente pelo Instituto Nacional de Estudos e Pesquisas Educacionais Anísio Teixeira -
INEP (2004a), o Brasil possui 4,1 milhões de matrículas em cursos presenciais de graduação, das quais quase 3 milhões estão em instituições privadas, representando $71,7 \%$ do total, ou seja, de cada dez estudantes da educação superior no Brasil, sete estudam em instituições privadas e apenas três em instituições públicas.

Uma outra característica da educação superior no Brasil é a de que há 2.454.348 matrículas no período noturno, representando $58,9 \%$ do total, percentual crescente a cada ano. Deste montante, $82,7 \%$ das matrículas (2.029.054) está nas instituições privadas, o que representa que em cada dez estudantes do período noturno da educação superior no país, oito deles estão em instituições privadas.

Os dados indicam que a educação tornou-se um segmento de business, com alta atratividade para empresários, decorrente da base de sustentação presente na legislação e nas políticas e regulamentações, no sentido de se atender a uma demanda crescente, deixando para segundo plano questões relevantes tais como: qualidade do ensino, formação de professores, e sobretudo, a política de oferta de vagas pelo Estado no período noturno, objeto de estudo deste trabalho.

As políticas públicas para a educação superior implantadas pelos governos pós-64 foram inicialmente direcionadas para atender às necessidades decorrentes da expansão do desenvolvimento econômico e às exigências impostas pelo mercado de trabalho (SOUZA, 1981). No período de 1960-1980, a pressão do mercado para ampliação do sistema educacional era crescente tendo como uma das causas a situação no final dos anos 60, devido ao elevado número de alunos excedentes (aprovados nos exames vestibulares de universidades públicas, mas que não 
podiam ser admitidos por falta de vagas). Por exemplo, o número de excedentes em 1969 superava o índice de 161 mil, quantidade que equivalia à quantidade total de matrículas de 1965 (SAMPAIO, 2000).

A conjuminância desses fatores favoreceu a expansão do setor privado nas décadas de 70 e 80, mediante a multiplicação de instituições de pequeno porte, muitas das quais, segundo Sampaio (2000), resultantes da transformação de antigas escolas secundárias. A autora apresenta dados do Núcleo de Pesquisas sobre o Ensino Superior - Nupes/USP, indicativos do crescimento dos estabelecimentos privados de ensino superior, que em 1970 representavam 43,4\% do total; em 1975, $75,0 \%$ e em 1980, 77,3\%. Quanto às matrículas no setor privado, em 1970 representavam 50,5\%; em 1975, 61,8\% e em 1980, $64,3 \%$. A expansão do setor privado ocorreu por meio da oferta de novas carreiras, sobretudo nas áreas sociais e profissionalizantes à época, favorecida pela Reforma Universitária de 1968, Lei n. 5.540 (BRASIL, 1968).

A partir da segunda metade da década de 70 inicia-se um processo de fusão e aquisição de escolas privadas, com a transformação de estabelecimentos isolados em federação de escolas ou escolas integradas. $\bigcirc$ movimento seguinte, no final da década de 80 é o da transformação de escolas isoladas ou de federação de escolas em universidades privadas. No período de 1980 a 1995, o ensino privado tem sua participação percentual estagnada no número total de matrículas tendo, inclusive, em alguns momentos apresentado decréscimo (PALMA FILHO, 2005).

No final do século passado e no início deste, novo crescimento na participação do setor privado é observado, passando do patamar de $60 \%$ para a faixa dos $70 \%$. A Tabela 1 indica o predomínio progressivo de matrículas no setor privado e o arrefecimento no setor público, a partir da década de 70, no país.

Tabela 1 - Matrículas no ensino superior no Brasil (1960 a 2004): setor público e privado.

\begin{tabular}{|l|c|c|c|c|c|}
\hline \multirow{2}{*}{ Ano } & Total de & \multicolumn{2}{|c|}{ Setor Público } & \multicolumn{2}{c|}{ Setor Privado } \\
\cline { 2 - 6 } & Matrículas & Matrículas & Participação & Matrículas & Participação \\
\hline 1960 & 226.218 & 132.250 & $58,5 \%$ & 93.968 & $41,5 \%$ \\
\hline 1970 & 425.475 & 210.610 & $49,5 \%$ & 214.865 & $50,5 \%$ \\
\hline 1980 & 1.377 .286 & 492.232 & $35,7 \%$ & 885.054 & $64,3 \%$ \\
\hline 1985 & 1.367 .609 & 556.680 & $40,7 \%$ & 810.929 & $59,3 \%$ \\
\hline 1990 & 1.540 .080 & 578.625 & $37,6 \%$ & 961.455 & $62,4 \%$ \\
\hline 1995 & 1.759 .703 & 700.540 & $39,8 \%$ & 1.059 .163 & $60,2 \%$ \\
\hline 2000 & 2.694 .245 & 887.026 & $32,9 \%$ & 1.807 .219 & $67,1 \%$ \\
\hline 2004 & 4.163 .733 & 1.178 .328 & $28,3 \%$ & 2.985 .405 & $71,7 \%$ \\
\hline
\end{tabular}

Fontes: Dados de 1960 e 1970 - Nupes/USP. Ver Sampaio (2000, p. 52).

Dados de 1980 a 2004. Ver INEP (1999 a, 2005 a). 
A Tabela 2 apresenta o número de instituições de educação superior no país por tipo, cuja criação, diversificação e diferenciação estão consubstanciadas na própria LDB e em dispositivos posteriores, como o artigo $7^{\circ}$, do Decreto $n^{\circ} 3.860 / 2001$ (BRASIL, 2004), ao definir que: "Quanto à sua organização acadêmica, as instituições de ensino superior do Sistema Federal de Ensino classificam-se em: I - Universidades; II - Centros Universitários; e III - Faculdades Integradas, Faculdades, Institutos Superiores ou Escolas Superiores". É notória a expansão do setor privado em todos os tipos de instituição de educação superior, detendo: 50,9\% das Universidades, 97,2\% dos Centros Universitários; 97,5\% das Faculdades Integradas, 94,2\% das Faculdades, Escolas e Institutos e 66,0\% dos Centros de Educação de Tecnologia (CET) e Faculdades de Tecnologia (FaT).

Tabela 2 - Instituições de Educação Superior (2004)

\begin{tabular}{|l|c|c|c|c|c|}
\hline \multirow{2}{*}{$\begin{array}{l}\text { Tipo de } \\
\text { Instituição }\end{array}$} & Total & \multicolumn{2}{|c|}{ Setor Público } & \multicolumn{2}{c|}{ Setor Privado } \\
\cline { 2 - 6 } & Unidades & Unidade & $\%$ & Unidade & $\%$ \\
\hline Universidades & 169 & 83 & $49,1 \%$ & 86 & $50,9 \%$ \\
\hline Centros Universitários & 107 & 3 & $2,8 \%$ & 104 & $97,2 \%$ \\
\hline Faculdades Integradas & 119 & 3 & $2,5 \%$ & 116 & $97,5 \%$ \\
\hline Faculdades, Escolas e Institutos & 1.474 & 86 & $5,8 \%$ & 1.388 & $94,2 \%$ \\
\hline CET/FaT & 144 & 49 & $34,0 \%$ & 95 & $66,0 \%$ \\
\hline Total & 2.013 & 224 & $11,1 \%$ & 1.789 & $88,9 \%$ \\
\hline
\end{tabular}

Fonte: INEP (2005a).

A título de informação histórica, em 1980 o país possuía 65 universidades, das quais 45 públicas e 20 privadas; no período de 1980 a 2004 o número de universidades públicas quase que dobrou (passando de 45 para 83), ao passo que o de universidades privadas, mais que quadruplicou (passando de 20 para 86). Na Tabela 3 é apresentada a quantidade de instituições privadas com atuação na educação superior no período de 1998 a 2004, evidenciando o significativo crescimento quantitativo ocorrido (média anual de superior a 15\%).

Tabela 3 - Instituições privadas: educação superior (1998-2004).

\begin{tabular}{|l|c|c|}
\hline Ano & Número de instituições privadas & \% crescimento \\
\hline 1998 & 764 & - \\
\hline 1999 & 905 & $18,5 \%$ \\
\hline 2000 & 1.004 & $10,9 \%$ \\
\hline 2001 & 1.208 & $20,3 \%$ \\
\hline 2002 & 1.442 & $19,4 \%$ \\
\hline 2003 & 1.562 & $8,3 \%$ \\
\hline 2004 & 1.789 & $14,5 \%$ \\
\hline
\end{tabular}

Fonte: INEP (1999a, 2000, 2001, 2002, 2003, 2004, 2005a). 
Na Tabela 4 são apresentadas as dez maiores universidades brasileiras em número de matrículas. Há sete instituições priva- das, três estaduais e nenhuma federal, evidenciando-se o domínio do setor privado na educação superior do país.

Tabela 4 - Maiores universidades brasileiras em matrículas (2003).

\begin{tabular}{|l|l|c|c|c|}
\hline Ordem & Instituição de Ensino & UF & $\begin{array}{c}\text { Categoria } \\
\text { Administrativa }\end{array}$ & Matrículas \\
\hline 1 & Universidade Estácio de Sá & RJ & Privada & 100.617 \\
\hline 2 & Universidade Paulista & SP & Privada & 92.023 \\
\hline 3 & Universidade de São Paulo & SP & Estadual & 44.281 \\
\hline 4 & Universidade Luterana do Brasil & RS & Privada & 41.450 \\
\hline 5 & Pontifícia Universidade Católica de Minas Gerais & MG & Privada & 36.749 \\
\hline 6 & Universidade Salgado de Oliveira & RJ & Privada & 35.719 \\
\hline 7 & Universidade Estadual do Piauí & PI & Estadual & 35.683 \\
\hline 8 & Universidade Estadual de Goiás & GO & Estadual & 34.113 \\
\hline 9 & Universidade Bandeirante de São Paulo & SP & Privada & 32.852 \\
\hline 10 & Universidade do Vale do Rio dos Sinos & RS & Privada & 31.482 \\
\hline
\end{tabular}

Fonte: INEP (2004 a).

Santos (2004) denomina o setor privado de "produtor de serviços", afirmando que há produtores muito antigos, porém, esclarece que a maioria surgiu nas duas últimas décadas. Distingue, ainda, os produtores cooperativos, solidários e não-lucrativos, que formam verdadeiras universidades, da grande maioria daqueles que têm fins lucrativos, e que nos piores casos são meras fábricas de diplomas de pouco valor.

As políticas desenvolvidas no Brasil para o ensino superior têm gerado resultados duvidosos quanto ao esperado progresso técnico-científico e de bem-estar, pois as desigualdades nos extremos vêm se aprofundando. Vaidergorn (2001, p. 85) apresen- ta dados importantes para se pensar a extensão do ensino superior como indicador de competitividade entre países emergentes e em desenvolvimento, que explicam o distanciamento desses extremos e o lugar ocupado pelos países na busca da modernidade. Dados da UNESCO de 1994 e 1995 (apud TRIGUEIRO, 2003), indicavam que os Estados Unidos possuíam 72,4\% de seus universitários nas instituições públicas; a França, 92,2\%; a Inglaterra, 99,9\%; a Argentina 90,0\%; enquanto o Brasil, apenas $41,6 \%$ das vagas em universidades públicas ${ }^{2}$. $\bigcirc$ distanciamento do Brasil da modernidade tornou-se mais evidente quando se divulgou que dos 43,6 milhões de estudantes brasileiros matricu-

\footnotetext{
${ }^{2}$ Há na cultura brasileira um senso comum de associar aquilo que é público como sendo gratuito, o que não ocorre em muitos países. Em diversos países o ensino superior oferecido pelo Estado é pago pelo estudante. Ressalta-se que não é objeto deste trabalho discutir a questão da gratuidade ou não das instituições públicas, uma vez que para se realizar uma análise nesta área exigir-se-iam pesquisas e avaliações aprofundadas em termos de sistema econômico-tributário brasileiro e dos serviços públicos oferecidos à população.
} 
lados em todos os níveis de ensino, somente $3,8 \%$ cursava uma faculdade, ou seja, 1.661 .034 alunos, o mesmo índice de $41,6 \%$ anteriormente citado (BRUNNER, 1994 apud VAIDERGORN, 2001, p. 85).

Ainda segundo Vaidergorn (2001), o crescimento na oferta de vagas na rede particular de ensino superior no Brasil contraria indicadores de países desenvolvidos. governo federal em muito facilitou a proliferação de cursos particulares como forma de suprir as vagas demandadas pelo mercado, que as instituições públicas não conseguiam atender por meio de cursos de graduação. Assim, o Estado desobrigouse do atendimento a estas demandas, propiciando a criação de um forte setor de ensino superior composto por faculdades particulares, transformando-se em verdadeiras empresas, poderosas e rentáveis. Dados de 2004 do INEP indicam que apenas $28,3 \%$ do total das matrículas está em instituições públicas no país, evidenciando que o domínio das instituições privadas na educação superior no país vem, ao longo do tempo, alastrando-se de forma incontestável e irreversível.

\section{Histórico dos cursos noturnos no Brasil e a situação atual}

De acordo com Spósito (1986), somente na década de 50 foi iniciada a discussão sobre a utilização de prédios dos grupos escolares que ficavam ociosos no período da noite, a fim de ampliar as vagas para o curso ginasial, como alternativa para viabilizar acesso aos jovens das classes trabalhadoras. Este relato é ratificado por Furlani (1998), quando afirma que nos anos 50 a população brasileira reivindica- va o acesso à escola secundária (antigo ginásio) exigindo a criação de vagas adicionais no período noturno.

De modo análogo, no início dos anos 60 a luta dos estudantes excedentes por vagas nos cursos superiores implicou a abertura de faculdades no período noturno, ou seja, há cerca de 200 anos existem cursos superiores no Brasil, porém os cursos noturnos, que atualmente representam a maior parcela do número de matrículas, foram iniciados há menos de 50 anos. Assim, a tradicional frase "estudar para poder trabalhar" teve de ser alterada para "trabalhar para poder estudar", conforme constata Gonçalves (1987, p. 11):

$\mathrm{Se}$, em condições normais, o estudo deveria preceder ao trabalho, de modo que, somente após completada a formação escolar e profissional, o estudante passasse a exercer a atividade profissional, a realidade dos fatos, emergente das condições socioeconômicas, reúne freqüentemente, na pessoa do trabalhador, a dupla condição de empregado e estudante. Inverteram-se de há muito, os termos da proposição: em lugar de estudar para poder trabalhar, trabalha-se para poder estudar.

Atualmente esse quadro pouco se alterou com a promulgação da LDB (BRASIL, 1996), que reserva para a educação superior a possibilidade de descentralização e flexibilização, além de novas formas de controle e padronização avaliativos, que facilitaram a expansão de instituições privadas e do ensino noturno.

Artigo 47, $\S 4^{\circ}$, da LDB (BRASIL, 1996), na tentativa de assegurar o mesmo nível de qualidade do ensino diurno ao 
noturno, define que "as instituições de educação superior oferecerão no período noturno, cursos de graduação nos mesmos padrões de qualidade mantidos no período diurno, sendo obrigatória a oferta noturna nas instituições públicas, garantida a necessária previsão orçamentária". No entanto, passados dez anos de sua promulgação, discute-se ainda o cumprimento desse dispositivo, porque não há avaliações e indicadores acerca da qualidade dos cursos por período.

O INEP (2004a) aponta pelo Censo Anual da Educação Superior de 2003 que dos 1.081 municípios brasileiros com cursos de graduação, em 252 deles a educação superior é ministrada exclusivamente no período noturno. Isto representa que a cada quatro cidades com cursos superiores, uma disponibiliza somente cursos no período noturno. Na rede pública, a situação não é diferente: dos 703 municípios que têm cursos de graduação mantidos por instituições federais, estaduais ou municipais, em 85 deles as aulas são ministradas exclusivamente à noite. Ainda segundo o INEP, as características dos estudantes são semelhantes, pois a maioria deles trabalha no município onde está localizada a instituição ou em cidades vizinhas, tendo como única oportunidade para concluir a graduação, a realização de estudos no período noturno (INEP, 2004b). Esta informação ratifica a importância da educação superior no período noturno no país.

De acordo com o Censo Anual da Educação Superior de 2004 (INEP, 2005a), há no Brasil cerca de 2,5 miIhões de matrículas em cursos de graduação presenciais no período noturno - este número, por sua grandeza, já me- receria algumas análises e reflexões por parte da sociedade. $\bigcirc$ período noturno contempla a maior parcela dos estudantes, com 58,9\% do total. Esta dominância vem-se caracterizando como uma realidade nacional nos últimos sete censos divulgados pelo INEP. Entretanto, há ainda que se destacar que este percentual tem crescido anualmente, conforme apresentado no Gráfico 1, que indica uma tendência para os próximos anos.

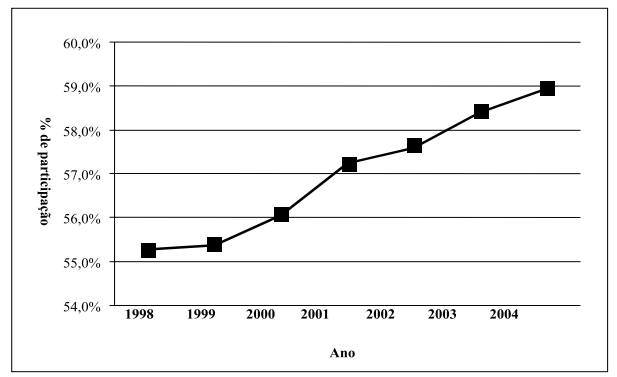

Gráfico 1 - Participação percentual das matrículas no período noturno na educação superior no Brasil - Cursos de Graduação (1998 a 2004).

Fonte: INEP (1999 a, 2005a).

Pela Tabela 5 pode-se constatar tanto o crescimento numérico das matrículas no período noturno, quanto a evolução do percentual de participação nesse período. O cruzamento dos dados desta tabela com os da Tabela 1 permite verificar que a expansão de matrículas no ensino superior noturno foi acompanhada do crescimento de matrículas nas instituições privadas. A Tabela 1 demonstra que em 2004, o setor público do ensino superior teve uma participação de $28,3 \%$ e o privado $71,7 \%$, sendo que este último manteve seus percentuais de participação em ascensão em 1995, 2000 e 2004, contrariamente ao que ocorreu no setor público. 
Tabela 5 - Matrículas no ensino superior no Brasil (1998 a 2004) - Total geral e período noturno

\begin{tabular}{|l|c|c|c|}
\hline \multirow{2}{*}{ Ano } & Total de Matrículas & Total de Matrículas & $\%$ \\
\cline { 2 - 4 } & Ensino Superior & (período noturno) & noturno \\
\hline 1998 & 2.125 .958 & 1.175 .367 & $55,3 \%$ \\
\hline 1999 & 2.369 .945 & 1.312 .058 & $55,4 \%$ \\
\hline 2000 & 2.694 .245 & 1.510 .338 & $56,1 \%$ \\
\hline 2001 & 3.030 .754 & 1.734 .936 & $57,2 \%$ \\
\hline 2003 & 3.479 .913 & 2.003 .755 & $57,6 \%$ \\
\hline 2004 & 3.887 .771 & 2.270 .653 & $58,4 \%$ \\
\hline
\end{tabular}

Fonte: INEP (1999 a, 2005 a).

Dentre as várias causas desse crescimento, uma delas decorre da tendência indicada por Santos (2004) em virtude das mudanças que a universidade vem sofrendo no processo de democratização de seu acesso, particularmente nos últimos dez anos, devido à forte demanda dos filhos de classes sociais menos favorecidas.

Há grandes indícios de que o índice de matrículas nas instituições de ensino superior privadas, e particularmente no ensino noturno, continuará em ascensão devido às políiticas do governo federal, como por exemplo o Programa Universidade para Todos - PROUNI. As bolsas oferecidas aos estudantes são integrais ou com $50 \%$ de desconto no valor da mensalidade, dependendo da renda familiar do estudante; em contrapartida, as instituições que aderem ao programa têm isenção de tributos federais.

Duas questões são colocadas em relação a esta política: a transferência de recursos públicos para as instituições privadas pela isenção de impostos ${ }^{3}$ e a qualidade dos cursos oferecidos pelas instituições conveniadas.
Takahashi (2006a) afirma que dos 492 cursos avaliados como ruins em 2004 e 2005 pelo ENADE (Exame Nacional de Desempenho de Estudantes), 237 (48\% do total) oferecem vagas no PROUNI. Assim, a qualidade da formação oferecida não está na pauta das políticas, valorizando-se muito mais os índices de acesso ao ensino superior. Mesmo com os méritos que essa política possa representar para os estudantes de baixa renda, é necessário frisar a condição de desigualdade em que os mesmos disputam vagas no mercado de trabalho, com seus concorrentes provenientes de cursos bem avaliados, com infra-estrutura adequada e realizados em condições bem menos adversas.

Sabe-se que a realidade brasileira do período noturno é, em geral, caracterizada por estudantes que trabalham durante o dia, em área não necessariamente associada a seu interesse, o que os leva a tentar obter recursos financeiros para realizar o curso superior. Esses estudantes enfrentam, de modo mais intenso, problemas diários no

${ }^{3} \mathrm{Em}$ 2005, primeiro ano do programa, o governo deixou de arrecadar $\mathrm{R} \$ 105,6$ milhões e beneficiou 112.275 alunos, distribuídos entre 1.142 instituições, ou seja, "o número de vagas do PROUNl é quase o mesmo do oferecido pelos vestibulares de todas as universidades federais do país - cerca de 120 mil alunos" (O NÚMERO de vagas do PROUNI é..., 2006, p. C1) 
trânsito e transportes, implicando atrasos e perdas de aulas, conforme indicam Terribili Filho e Raphael (2005). Mesmo assim buscam, por meio da educação superior, o reconhecimento social, formação profissional e obtenção de um diploma, na expectativa de aumentar suas chances de competição no mercado de trabalho, melhorar suas condições de vida, sonhos de todo cidadão. Na visão de marketing das instituições de ensino superior, o diploma é apresentado como um "produto" valorizado pela sociedade e que pode inclusive ter "grife" (SAMPAIO, 2000, p. 348).

Mesmo em um mundo incerto de trabaIho, há indicações de que os indivíduos que possuem escolaridade maior estão à frente nas suas remunerações, quando comparados àqueles que têm menos anos de banco escolar. Estudo realizado por Medeiros (2004, p. A21), economista do Instituto de Pesquisa Econômica Aplicada (IPEA), apresenta os ganhos médios que cada ano de educação acresce à renda do trabalhador brasileiro. Afirma o pesquisador, que "na média um ano de estudo representa um acréscimo de 18\% em relação ao rendimento de um sujeito que nunca tenha ido à escola. Quinze anos ou mais, $754 \%$ a mais na conta do cidadão". Por outro lado, o mesmo estudo também indica que o curso superior completo, em si, não aumenta a fatia daqueles que se tornam ricos. Medeiros (2004) complementa que: "Você não é elite porque tem ensino superior. As pessoas são da elite porque têm a melhor educação disponível no país. As famílias estão transmitindo seu status para seus filhos". Assim, ter a melhor educação representa não só o acesso ao ensino de qualidade em todos os níveis, desde a educação básica, como também o acesso ao legado de conhecimento e de cultura transmitidos aos filhos.

\section{A Constituição Paulista e a política de oferta de vagas pelas universidades públicas paulistas}

Estado de São Paulo, segundo dados do Censo Anual do Ensino Superior de 2004, tem o maior contingente de matrículas do país, ou seja, 1.109.693 representando $26,7 \%$ do total nacional. A concentração de matrículas no Estado no período noturno é a maior do país com 765.442, representando 69,0\% do total estadual; resumidamente pode-se dizer dentre dez estudantes do Estado de São Paulo, sete estão matriculados no período noturno. Como informação adicional, a fim de evidenciar a representatividade quantitativa, as 765 mil matrículas no período noturno no Estado de São Paulo superam o número de matrículas dos demais estados brasileiros, independentemente do período analisado: Rio de Janeiro (total de 444 mil matrículas), Minas Gerais (420 mil), Rio Grande do Sul (322 mil), Paraná (292 mil), Santa Catarina (178 mil), Bahia (167 mil) e os demais com quantidade de matrículas inferior a 150 mil.

As três universidades estaduais paulistas, UNESP, UNICAMP e USP que, além de atividades de ensino realizam pesquisas e prestam serviços à comunidade em diversas cidades do Estado de São Paulo, ofereceram em 2006, um total de 18.956 vagas, assim distribuídas: USP (9.952 vagas, representando $52,5 \%$ deste total), UNESP (6.174 vagas, representando 32,6\% deste total) e UNICAMP (2.830 vagas, 14,9\%).

A USP foi criada em 1934, e a UNICAMP em 1966. A UNESP em 1976, com a incorporação de unidades universitárias distribuídas por diferentes cidades do interior paulista, os então chamados Institutos Isolados de Ensino Superior do Estado de São Paulo, abrangen- 
do diversas áreas do conhecimento. Tais unidades haviam sido criadas, em sua maior parte, no final de 1950 e início de 1960.

Há que se ressaltar que as três universidades estaduais paulistas foram incluídas entre as 500 melhores universidades do mundo no ano de 2005, conforme trabalho divulgado pelo Institute of Higher Education of Shanghai Jiao Tong University. Este trabalho é realizado anualmente e tem como metodologia a utilização de indicadores de qualidade para cada instituição, levando em consideração as pesquisas realizadas pelos corpos docente e discente, incluindo prêmios internacionais, citação de pesquisadores, publicação de artigos científicos, indexação de artigos e desempenho per capita de produção acadêmica. Estes indicadores recebem uma pontuação para cada item analisado permitindo que, desta forma, seja calculado um índice final para cada universidade. Destaca-se que na relação das 500 melhores universidades constam quatro brasileiras: as três estaduais paulistas e a Universidade Federal do Rio de Janeiro (UFRJ). Da América Latina, há também uma universidade argentina (Universidad de Buenos Aires), uma chilena (Universidad de Chile) e uma mexicana (Universidad Nacional Autónoma de México).
No Estado de São Paulo, a Constituição Paulista de 1989 (SÃO PAULO, 1989), em seu artigo 253, orienta o sistema de ensino superior das instituições públicas estaduais a ampliarem o número de vagas, mantendo os mesmos padrões de qualidade de ensino e de desenvolvimento da pesquisa. Em seu parágrafo único, prevê que as universidades públicas estaduais devam ofertar, no período noturno, uma quantidade de vagas equivalente a pelo menos um terço do total dessas vagas.

Esta medida levou a uma oferta crescente de vagas no período noturno nas instituições estaduais. Por exemplo, em 1989 o número de vagas oferecidas no período noturno da UNICAMP representava 8,0\% do total, em 2000 cresceu para 35,3\%, conforme registra Oliveira e Catani (2001).

Em 2004, 2005 e 2006, a oferta de vagas na UNICAMP para o período noturno manteve-se respectivamente em $31,7 \%, 31,7 \%$, e $31,4 \%$, conforme se constata pela Tabela 6. Analisando-se também, a distribuição de vagas por área de conhecimento (biomédicas, exatas e humanas), nota-se que o equilíbrio se mantém ao redor da faixa dos $30 \%$. Os dados de 2004 são idênticos aos de 2005.

\section{Tabela 6 - Vagas oferecidas pela UNICAMP (2004, 2005 e 2006)}

\begin{tabular}{|l|c|c|c|c|}
\hline VAGAS 2004 e 2005 & Biomédicas & Exatas & Humanas & Total \\
\hline Diurno, vespertino ou integral & 435 & 1.020 & 465 & 1.920 \\
\hline Noturno & 175 & 490 & 225 & 890 \\
\hline Total geral & 610 & 1.510 & 690 & 2.810 \\
\hline$\%$ noturno & $28,7 \%$ & $32,5 \%$ & $32,6 \%$ & $31,7 \%$ \\
\hline VAGAS 2006 & & & & \\
\hline Diurno, vespertino ou integral & 435 & 1.020 & 485 & 1.940 \\
\hline Noturno & 175 & 490 & 225 & 890 \\
\hline Total geral & 610 & 1.510 & 710 & 2.830 \\
\hline \% noturno & $28,7 \%$ & $32,5 \%$ & $31,7 \%$ & $31,4 \%$ \\
\hline
\end{tabular}

Fonte: COMVEST (2006). 
Quanto à UNESP, com faculdades em 16 cidades do Estado de São Paulo, há percentuais de oferta de vagas para o período noturno que excedem a exigência da Constituição Paulista, tendo apresentado em 2004, 2005 e 2006 respectivamente, $34,8 \%, 36,3 \%$ e $36,2 \%$. Entretanto, devese ressaltar que o número total de vagas ofertadas nestes três anos, praticamente se manteve constante: $6.310,6.135$ e 6.174 .
Pela Tabela 7, pode-se notar que o percentual de vagas oferecidas nos cursos noturnos na UNESP não tem uma distribuição equilibrada entre as áreas de conhecimento, pois na área de ciências biológicas, o percentual não atinge nem 20\%, ao passo que na área de ciências humanas este percentual quase chega a $50 \%$. Esta característica ocorre nos três anos apresentados: 2004, 2005 e 2006.

Tabela 7 - Vagas oferecidas pela UNESP (2004, 2005 e 2006)

\begin{tabular}{|l|c|c|c|c|}
\hline VAGAS 2004 & Biomédicas & Exatas & Humanas & Total \\
\hline Diurno, vespertino ou integral & 1.505 & 1.240 & 1.366 & 4.111 \\
\hline Noturno & 350 & 570 & 1.279 & 2.199 \\
\hline Total geral & 1.855 & 1.810 & 2.645 & 6.310 \\
\hline$\%$ noturno & $18,9 \%$ & $31,5 \%$ & $48,4 \%$ & $34,8 \%$ \\
\hline VAGAS 2005 & Biomédicas & Exatas & Humanas & Total \\
\hline Diurno, vespertino ou integral & 1.505 & 1.100 & 1.306 & 3.911 \\
\hline Noturno & 360 & 570 & 1.294 & 2.224 \\
\hline Total geral & 1.865 & 1.670 & 2.600 & 6.135 \\
\hline$\%$ noturno & $19,3 \%$ & $34,1 \%$ & $49,8 \%$ & $36,3 \%$ \\
\hline VAGAS 2006 & Biomédicas & Exatas & Humanas & Total \\
\hline Diurno, vespertino ou integral & 1.515 & 1.105 & 1.320 & 3.940 \\
\hline Noturno & 360 & 570 & 1.304 & 2.234 \\
\hline Total geral & 1.875 & 1.675 & 2.624 & 6.174 \\
\hline$\%$ noturno & $19,2 \%$ & $34,0 \%$ & $49,7 \%$ & $36,2 \%$ \\
\hline
\end{tabular}

Fontes: Dados de 2004: ver VUNESP (2004).

Dados de 2005 e 2006: ver UNESP $(2005,2006)$.

histórico dos últimos três anos na USP, aponta situação idêntica à da UNESP, conforme dados contidos na Tabela 8, ou seja, em $2006,34,8 \%$ de vagas oferecidas no período noturno. Entretanto, quanto à distribuição por áreas constatam-se distorções: $16,5 \%$ em ciências biológicas, $25,8 \%$ em ciências exatas e $50,2 \%$ em humanidades. 
Tabela 8 - Vagas oferecidas pela USP (2004, 2005 e 2006).

\begin{tabular}{|l|c|c|c|c|}
\hline VAGAS 2004 & Biomédicas & Exatas & Humanas & Total \\
\hline Diurno, vespertino ou integral & 1.703 & 2.110 & 1.832 & 5.645 \\
\hline Noturno & 325 & 630 & 1.947 & 2.902 \\
\hline Total geral & 2.028 & 2.740 & 3.779 & 8.547 \\
\hline$\%$ noturno & $16,0 \%$ & $23,0 \%$ & $51,5 \%$ & $34,0 \%$ \\
\hline VAGAS 2005 & Biomédicas & Exatas & Humanas & Total \\
\hline Diurno, vespertino ou integral & 1.883 & 2.230 & 2.042 & 6.155 \\
\hline Noturno & 325 & 810 & 2.277 & 3.412 \\
\hline Total geral & 2.208 & 3.040 & 4.319 & 9.567 \\
\hline$\%$ noturno & $14,7 \%$ & $26,6 \%$ & $52,7 \%$ & $35,7 \%$ \\
\hline VAGAS 2006 & Biomédicas & Exatas & Humanas & Total \\
\hline Diurno, vespertino ou integral & 1.898 & 2.330 & 2.262 & 6.490 \\
\hline Noturno & 375 & 810 & 2.277 & 3.462 \\
\hline Total geral & 2.273 & 3.140 & 4.539 & 9.952 \\
\hline$\%$ noturno & $16,5 \%$ & $25,8 \%$ & $50,2 \%$ & $34,8 \%$ \\
\hline
\end{tabular}

Fonte: FUVEST $(2004,2005,2006)$.

Um ponto a se destacar no caso da USP foi o crescimento na oferta de vagas ocorrido em 2005, quando passou de 8.547 para 9.567. As 1.020 vagas criadas nesse ano foram decorrentes da criação da USP Leste em 30 de agosto de 2004, no bairro de Ermelino Matarazzo, localizado na zona leste da cidade de São Paulo, em uma clara intenção do Governo do Estado de distribuir geograficamente pela cidade os cursos e vagas da USP, já que a maior parte das vagas está na zona oeste da cidade, no bairro do Butantã. $\mathrm{Na}$ USP Leste foram criados diversos cursos até então inéditos na instituição, tais como: Gestão de Políticas Públicas, Tecnologia Têxtil e Indumentária, Lazer e Turismo, Gestão Ambiental, Gerontologia, Marketing e outros. Do total de 1.020 vagas oferecidas, 420 foram destinadas ao período noturno, ou seja, $41,2 \%$.

Quando se analisa o total de vagas oferecido pelas três universidades paulistas em 2006
(Tabela 9), verifica-se que a determinação contida na Constituição Paulista é plenamente atendida, ou seja, $34,7 \%$ das vagas são para o período noturno; entretanto, há um desequilibrio entre as áreas de conhecimento, uma vez que a área de ciências biológicas está muito aquém de um terço $(19,1 \%)$, a de ciências exatas está próxima a um terço, com $29,6 \%$ e a de ciências humanas excede a meta com $48,3 \%$, possibilitando assim, compensar numericamente a carência nas demais áreas. A discrepância quantitativa entre as áreas é evidente, o que ratifica críticas efetuadas por algumas entidades de que 0 acesso e a escolha por cursos noturnos ainda apresentam limitações, pois, a maior oferta de vagas ocorre nas áreas de conhecimento socialmente menos valorizadas.

A questão de oferta de vagas nas universidades estaduais paulistas deve-se agravar, já que o número de inscritos nos vesti- 
bulares nas três universidades estaduais paulistas continua em ascensão. Para 2007 estas universidades oferecerão somente 25 vagas adicionais em relação a 2006, devido à falta de recursos. Dados das instituições revelam que houve aumento de 1,8\% no número de professores entre 2002 e 2004 e um decréscimo de $0,1 \%$ no quadro de funcionários, ao passo que a oferta de vagas no vestibular subiu $21,7 \%$, para 0 mesmo período, conforme Takahashi (2006b). A desaceleração na oferta de vagas as dificuldades financeiras, a falta de professores e de funcionários e o número excessivo de alunos em salas de aulas não são exclusividades dessas três universidades, mas têm-se tornado regra em todo o ensino superior público, o que restringe mais ainda as demandas das classes socialmente menos favorecidas.

\section{Tabela 9 - Quadro total de vagas oferecidas em 2006: UNESP, UNICAMP e USP.}

\begin{tabular}{|l|c|c|c|c|}
\hline VAGAS & Biomédicas & Exatas & Humanas & Total \\
\hline Diurno, vespertino ou integral & 3.848 & 4.455 & 4.067 & 12.370 \\
\hline Noturno & 910 & 1.870 & 3.806 & 6.586 \\
\hline Total geral & 4.758 & 6.325 & 7.873 & 18.956 \\
\hline$\%$ noturno & $19,1 \%$ & $29,6 \%$ & $48,3 \%$ & $34,7 \%$ \\
\hline
\end{tabular}

Fontes: Dados UNESP: ver UNESP (2006).

Dados UNICAMP: ver COMVEST (2006).

Dados USP: ver FUVEST (2006).

Das 18.956 vagas ofertadas em 22 municípios paulistas pelas três universidades estaduais, 6.586 referem-se ao período noturno. A despeito dos benefícios que a política de oferta de vagas assegurada pela Constituição Paulista para o ensino noturno possa representar, o total de 6.586 vagas equivale a um percentual inferior a $1 \%$ do total de 765.442 matrículas na educação superior no Estado de São Paulo, evidenciando a pouca efetividade quantitativa da atual legislação frente à demanda existente.

A necessidade de o governo avaliar e redimensionar as políticas para o ensino superior é urgente. Para que não se crie mais uma categoria de excluídos; daqueles que não concluem o ensino superior ou daqueles que concluem mas, devido à de- fasagens na educação básica, aliadas à má qualidade do ensino superior, especialmente em determinadas instituições particulares, sucumbem diante do primeiro processo seletivo para o trabalho.

Dados do Censo da Educação de 2003 revelavam o lado contraditório das políticas de ampliação quantitativa de acesso ao ensino superior, em que apenas $42 \%$ dos estudantes ingressantes consegue terminar a faculdade (CUCOLO, 2004). Uma outra pesquisa apresentada pelo INEP, do Ministério da Educação MEC, com base na análise de questionários socioeconômicos aplicados a 143.170 estudantes ingressantes e concluintes da educação superior, que participaram do Exame Nacional de Desempenho dos Estudantes - ENADE, ano de 
2004, apontou percentuais incongruentes com a classe de renda familiar entre ingressantes e concluintes. Por exemplo, dos ingressantes, $24,4 \%$ possui renda familiar até 3 salários mínimos; dos concluintes, apenas $17,6 \%$ estão nessa faixa de renda familiar. Por outro lado, os ingressantes na faixa de renda acima de dez salários mínimos representam 26,1\%, ao passo que os concluintes dessa faixa de renda, 35,4\% (INEP, 2005b). Logo, não basta propor políticas, mas é necessário acompanhar os contornos que elas vão assumindo ao longo do tempo, fazer ajustes e investir recursos que assegurem, de fato, o acesso, a permanência e a conclusão dos cursos superiores em instituições bem avaliadas e de qualidade.

\section{Considerações finais}

Quais são as perspectivas que se anunciam no âmbito das proposições de políticas públicas para o ensino superior e em particular para o ensino noturno? Se por um lado, a LDB de 1996 (BRASIL, 1996), estabelece que a qualidade dos cursos noturnos deve ser a mesma oferecida aos cursos diurnos, por outro, indaga-se quais são os mecanismos que efetuam esse controle e monitoramento? Os questionamentos podem ser estendidos a outros aspectos na educação superior no período noturno, seja quanto à oferta de vagas, à distribuição delas por área de conhecimento, à quantidade de horas-aula ou quanto à política de formação de professores. Acrescidas a isto, as condições urbanas, sobretudo das grandes cidades brasileiras, têm-se mostrado adversas ao estudante do período noturno, causando-lhe atrasos na chegada à instituição de ensino, perda de aulas e provas, ocasionando a interrupção na construção de seus saberes.
Após 38 anos, uma nova Reforma Universitária foi encaminhada ao Congresso Nacional (junho de 2006), na forma de Projeto de Lei da Educação Superior, que segundo o MEC, visa "[...] democratizar, garantir o financiamento, ampliar o acesso e qualificar as universidades brasileiras". Ainda de acordo com o MEC, o texto da reforma foi discutido com cerca de 200 instituições, incluindo entidades da comunidade acadêmica, organizações empresariais e de trabalhadores e movimentos sociais urbanos e do campo. Trata-se da quarta versão do documento que foi originalmente formulado para o início das discussões, as quais têm-se arrastado por estes dois últimos anos.

Quanto ao ensino noturno, a proposta é que as instituições federais "deverão oferecer, pelo menos, um terço de seus cursos e matrículas de graduação no turno noturno, com exceção para os cursos em turno integral". A Constituição Paulista de 1989 (SÃO PAULO, 1989), já definiu este mesmo percentual que se mostrou muito aquém das demandas da sociedade. Considerando-se que atualmente, no país, 58,9\% das matrículas na educação superior está no período noturno, a Reforma Universitária deveria rever o percentual de vagas a ser destinado a esse período, bem como apoiar a realização de estudos e pesquisas que possibilitem uma definição consistente da distribuição do percentual de vagas no período noturno por área de conhecimento, compatível com a natureza, exigências, diretrizes curriculares e especificidades de cada curso.

A falta de investimentos do Governo Federal nas instituições públicas existentes, e na ampliação delas, a expansão descon- 
trolada de matrículas nas instituições privadas, e a diversificação de instituições que favorecem a privatização do conhecimento, compõem um conjunto explicativo que ainda dificulta a ampliação do acesso dos jovens brasileiros ao ensino superior.

Diante desse quadro, no processo de Reforma Universitária é urgente ordenar a expansão do ensino superior, de modo a aumentar o número de vagas no sistema público por meio da fixação de significativos incrementos anuais predefinidos, compatibilizar a relação de vagas oferecidas entre o sistema público e o privado em função das demandas da sociedade, avaliar a oferta de vagas para as diferentes áreas de conhecimento, garantir e controlar a qualidade do ensino noturno, visando a um projeto maior de desenvolvimento do país, ordenado pelo Estado e alicerçado na valorização da Educação.

\section{Referências}

ARONOWITZ, S. Contra a escolarização: educação e classe social. Currículo sem Fronteiras, Portugal, v. 5, n. 2, p. 5-39, jul./dez. 2005. Disponível em:

<http://www.curriculosemfronteiras.org/vol5iss2articles/aronowitz.pdf $>$. Acesso em: 29 out. 2006.

AZEVEDO, J. M. L. A educação como política pública. 3. ed. Campinas: Autores Associados, 2004.

BRASIL. Decreto $n^{\circ} 3.860$, de 9 de julho de 2001. Dispõe sobre a organização do ensino superior, a avaliação de cursos e instituições, e dá outras providências. Arquivos, Brasília, DF, 2004. Disponível em: < http://portal.mec.gov.br/sesu/arquivos/pdf/ DecN3860.pdf>.

Acesso em: 27 abr. 2007.

Lei $n^{\circ}$. 5.540, de 28 de novembro de 1968. Fixa normas de organização e funcionamento do ensino superior e sua articulação com a escola média, e dá outras providências. Diário Oficial da União, Brasília, DF, 1968. Disponível em: < http://www.prolei.inep.gov.br/prolei/>. Acesso em: 27 abr. 2007.

Lei $n^{\circ}$ 9.394, de 20 de dezembro de 1996. Estabelece as diretrizes e bases da educação nacional. Diário Oficial [da] República Federativa do Brasil, Brasília, DF, 23 dez. 1996. Seção 1.

Ministério da Educação. Projeto de lei da educação superior. Brasília, DF, Disponível em: <http://portal.mec.gov.br/arquivos/pdf/projetolei.pdf>. Acesso em: 18 jun. 2006.

COMVEST. Campinas, SP, 2006. Disponível em: <http://www.comvest.unicamp.br/ estatisticas/2006/cv_fasel.html >. Acesso em: 2 jul. 2006. 
CUCOLO, E. Apenas $42 \%$ dos estudantes conseguem terminar a faculdade. Folha de S. Paulo Online, São Paulo, 14 out. 2004. Disponível em: < $\underline{h t t p: / / w w w 1 . f o l h a . v o l . c o m . b r / ~}$ folha/educacao/ult305u16231.shtml>. Acesso em: 18 set. 2006.

CUNHA, L. A. Ensino superior e universidade no Brasil. In: LOPES, E. M.; FARIAS FILHO, L. M.; VEIGA, C. G. (Org.). 500 anos de educação no Brasil. 3. ed. Belo Horizonte: Autêntica, 2003.

FURLANI, L. M. T. A claridade da noite: os alunos do ensino superior noturno. São Paulo: Cortez, 1998.

FUVEST. Manual do candidato 2004. São Paulo, 2004. Disponível em: <http:// www.fuvest.br/vest2004/manual/03-carreiras.pdf>. Acesso em: 1 jul. 2006.

. Informes à imprensa 2005: lançamento do manual do candidato. São Paulo, 2005. Disponível em: <http://www.fuvest.br/vest2005/informes/ii032005.stm >. Acesso em: 1 jul. 2006.

. Informes à imprensa 2006: lançamento do manual do candidato. São Paulo, 2006. Disponível em: <http://www.fuvest.br/vest2006/informes/ii042006.stm >. Acesso em: 1 jul. 2006.

GONÇALVES, E. O estudante no direito do trabalho. São Paulo: LTR, 1987.

INSTITUTE OF HIGHER EDUCATION OF SHANGHAI JIAO TONG UNIVERSITY. Academic ranking of world universities 2005. Shangai, China, 2005. Disponível em: $<$ http://ed.sjtu.edu.cn/rank/2005/ARWU2005TOP500list.htm>. Acesso em: 2 jul. 2006.

INEP. Sinopse estatística da educação superior: graduação 1998. Brasília, DF, 1999.

. Sinopse estatística da educação superior: graduação 1999. Brasília, DF, 2000. . Sinopse estatística da educação superior: graduação 2000. Brasília, DF, 2001. . Sinopse estatística da educação superior: graduação 2001. Brasília, DF, 2002. . Sinopse estatística da educação superior: graduação 2002. Brasília, DF, 2003. $\overline{2004 a}$. Sinopse estatística da educação superior: graduação 2003. Brasília, DF, 
INEP. Sinopse estatística da educação superior: graduação 2004. Brasília, DF, 2005a.

INEP. Em 252 cidades, graduação só à noite. Brasília, DF, 2004b. Disponível em: $<\underline{h t t p: / / w w w . i n e p . g o v . b r / i m p r e n s a / n o t i c i a s / c e n s o / s u p e r i o r / n e w s 04 ~ 04 . h t m ~}>$. Acesso em: 16 jun. 2006.

Há mais ingressantes pobres na graduação do que concluintes. Boletim do $\overline{I N E P, ~ B r a s i ́ l i a, ~ D F, ~ a n o ~ 3, ~ n . ~ 89, ~} 18$ mai. 2005b. Disponível em: < http:// www.inep.gov.br/informativo/informativo89.htm>. Acesso em: 17 set. 2006.

MEDEIROS, M. Tempo de estudo não explica desigualdade. Folha de São Paulo, São Paulo, 24 out. 2004. p. A21.

OlIVEIRA, R. P.; CATANI, A. M. Avaliação do impacto da Constituição Paulista de 1989 na expansão do ensino superior público noturno. In: FERREIRA, N. S. C.; AGUIAR, M. A. S. Gestão da educação: impasses, perspectivas e compromissos. 3. ed. São Paulo: Cortez, 2001.

PALMA FILHO, J. C. Política educacional brasileira: educação brasileira numa década de incertezas (1990-2000): avanços e retrocessos. São Paulo: CTE Editora, 2005.

ROMANELLI, O. O. História da educação no Brasil. 25. ed. Petrópolis: Vozes, 2001.

SAMPAIO, H. Ensino superior no Brasil: o setor privado. São Paulo: FAPESP: HUCITEC, 2000 .

SANTOS, B. S. Pela mão de Alice: o social e o político na pós-modernidade. São Paulo: Cortez, 1995.

- A universidade no século XXI: para uma reforma democrática e emancipatória da Universidade. 2. ed. São Paulo: Cortez, 2004.

SIQUEIRA, M. M. O ensino superior e a universidade. RAE Eletrônica, São Paulo, v. 4, n. 1, jan./jun. 2005. Disponível em:

$<$ http://www.scielo.br/scielo.php?pid=S1676-56482005000100015\&script=sci_arttext\&tlng =en $>$. Acesso em: 29 out. 2006.

SOUZA, M. I. S. Os empresários e a educação: o IPES e a política educacional após 1964. Petrópolis: Vozes, 1981.

SPÓSITO, M. O ensino superior noturno e a democratização do acesso à universidade: debates e propostas INEP. Revista Brasileira de Estudos Pedagógicos, Brasília, DF, v. 67, n. 157, p. 617-647, set./dez. 1986. Mesa Redonda. 
TAKAHASHI, F. Bolsa do MEC beneficia 237 cursos ruins. Folha de S. Paulo, São Paulo, 28 ago. 2006a. Caderno Cotidiano, p. C1.

USP, Unesp e Unicamp freiam expansão. Folha de S. Paulo, São Paulo, 4 set. 2006b. Caderno Cotidiano, p. C1.

TERRIBILI FILHO, A.; RAPHAEL, H. S. Fatores de atrasos e faltas do estudante do ensino superior noturno: a perda de aulas, de provas e o impacto no seu aproveitamento e em avaliações. Avaliação, Campinas, SP, v. 10, n. 2, p. 117-135, jun. 2005.

TRIGUEIRO, M. G. S. Reforma universitária e mudanças no ensino superior no Brasil. Brasília, DF, 2003. Disponível em: <http://www.iesalc.unesco.org.ve/pruebaobservatorio/ documentos\%20pdf/Reformas\%20Brasil.pdf>. Acesso em: 18 jun. 2006.

UNESP. Estatística candidato-vaga: vestibular 2005. São Paulo, 2004. Disponível em: $<$ http://www.unesp.com.br/vestibular/pdf/2004/cand_vaga_dez_2004.pdf>. Acesso em: 15 jun. 2006.

UNESP. História da criação da UNESP. São Paulo, 2006. Disponível em:

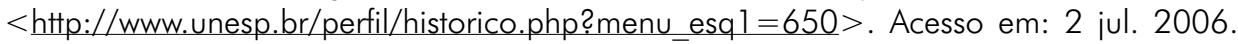

UNICAMP. Anuário estatístico UNICAMP 2003. Campinas, SP, 2003. Disponível em: <http://www.aeplan.rei.unicamp.br/anuario_estatistico_2003/indice_pdf.htm>. Acesso em: 10 abr. 2004.

VAIDERGORN, J. Uma perspectiva da globalização na universidade brasileira. Caderno CEDES, Campinas, SP, v. 21, n. 55, p. 78-91, nov. 2001.

VUNESP. Manual do candidato 2004. São Paulo, 2004. Disponível em: <http:// www.vunesp.com.br/vestibulares/vnsp0401/cursos.pdf>. Acesso em: 10 abr. 2004.

XAVIER, M. E.; RIBEIRO, M. L.; NORONHA, O. M. História da educação: a escola no Brasil. São Paulo: FTD, 1994.

Recebido em: 25/09/2006

Aceito para publicação em: 04/12/2006 